Volume 2, Issue 2, pages 157-168

\title{
Feasibility of Smartphone Camera Utilization and PowerPoint-based Video Analyzer on Kinematic Motion Experiment: An Inexpensive Method
}

\author{
E.D. Atmajati ${ }^{1, *}$, R.A. Salam ${ }^{2}$ \\ ${ }^{1}$ Department of Physics Education, Faculty of Teacher Training and \\ Education, Sanata Dharma University, Yogyakarta, Indonesia \\ ${ }^{2}$ Department of Physics Engineering, School of Electrical Engineering, \\ Telkom University, Bandung, Jawa Barat, Indonesia \\ *Corresponding Author: dian.atmajati@usd.ac.id
}

(Received 30-06-2020; Revised 21-07-2020; Accepted 21-07-2020)

\begin{abstract}
This study reports on the use of smartphone camera and power point application to analyze the kinematic motion experiment. This method is intended to make a better understanding of student's concept using the tools that are commonly owned by students. The experiments performed in this study were one-dimensional (1-D) represented by falling motion and twodimensional (2-D) using parabolic motion. In evaluating the experimental results, the obtained data were compared to the theoretical values that were calculated using analytical approach. The use of this method shows great measurement results in showing dependency of falling motion due to gravitational acceleration and proofing the constant velocity at projectile motion on its horizontal plane in which it is comparable to the theoretical value. The video analyzation method also can be used as an alternative solution to the established software, even better when the higher resolution camera and frame rate were used. Noting that the tools used in the
\end{abstract}




\section{International Journal of Applied Sciences and Smart Technologies}

Volume 2, Issue 2, pages 157-168

p-ISSN 2655-8564, e-ISSN 2685-9432

experiment were common around, thus, this can be used as a replacement for the advance tools.

Keywords: experimental analysis, kinematic motion, physics education, power point, smartphone camera

\section{Introduction}

Nowadays, misconceptions become one of a problem in physics learning [1,2]. For example, on kinematics subjects, students think if a free-fall motion is not only caused by gravitational acceleration, or another example, there is acceleration on the horizontal motion in projectile motion case. In overcoming the problems, experiments can be a solution due to the direct observation of physics phenomena by students [3]. So, they can relate the phenomena to the theory and then increase their understanding [1-4]. Various devices have been used to make an easy understanding demonstration tool, such as computer-based instrumentation tool [5], game controller [1-2], camera [6-11], and smartphones [1-2,12-13]. Among the others, smartphones are widely used because it has been embedded with various sensors [1-2,14]. The smartphone not only used on academics but also for other applications like spectroscopy analysis, psychiatric and medical examination, and also health monitoring [14].

In order to perform kinematic experiments, some previous studies usually use a camera to take video and then tracking the motion using various video analyzer software [7-11] besides using smartphones on mapping the motion through their accelerometer or gyroscope sensor, due to their easiness on taking video. However, the cameras used in the experiment generally are high-speed digital camera. Moreover, after being captured, the videos are analyzed using additional tools such as LoggerPro, Video Point, Measurement in Motion which are highly paid commercial software [15]. There is some free software such as Physics ToolKit, Tracker, and many others, usually, it can display the digitizing coordinates automatically. However, this often causes students or users to not pay too much attention to the process of moving observed objects. Therefore, to make students paying attention to the process, the motion analysis needs to be completed by the students directly. In this paper, Microsoft PowerPoint 


\section{International Journal of Applied Sciences and Smart Technologies}

Volume 2, Issue 2, pages 157-168

p-ISSN 2655-8564, e-ISSN 2685-9432

application will be used as a video analyzer to help students know about process of observed object movement. Previously, Microsoft PowerPoint has been used to measure angles on digitalized radiographic images [16] and diagnose sagittal cephalometric [17].

\section{Research Methodology}

The experiments used in this study are one-dimensional (1-D) and two-dimensional (2-D) kinematics motion experiments which are represented by free fall and projectile motion, respectively. In this experiment, a tennis ball was used as an observed object. It was recorded by $6 \mathrm{MP}$ Canon D6000 that can take 30 frames per second (fps). In addition, a Samsung Galaxy A30 that has a 16 MP camera was then used as an alternative solution to perform the experiment further. The smartphone camera can capture video for 30 frames per second (fps) with a Full HD (1080p) resolution video. Besides, the phone was embedded with slow motion feature which will be elaborated further.

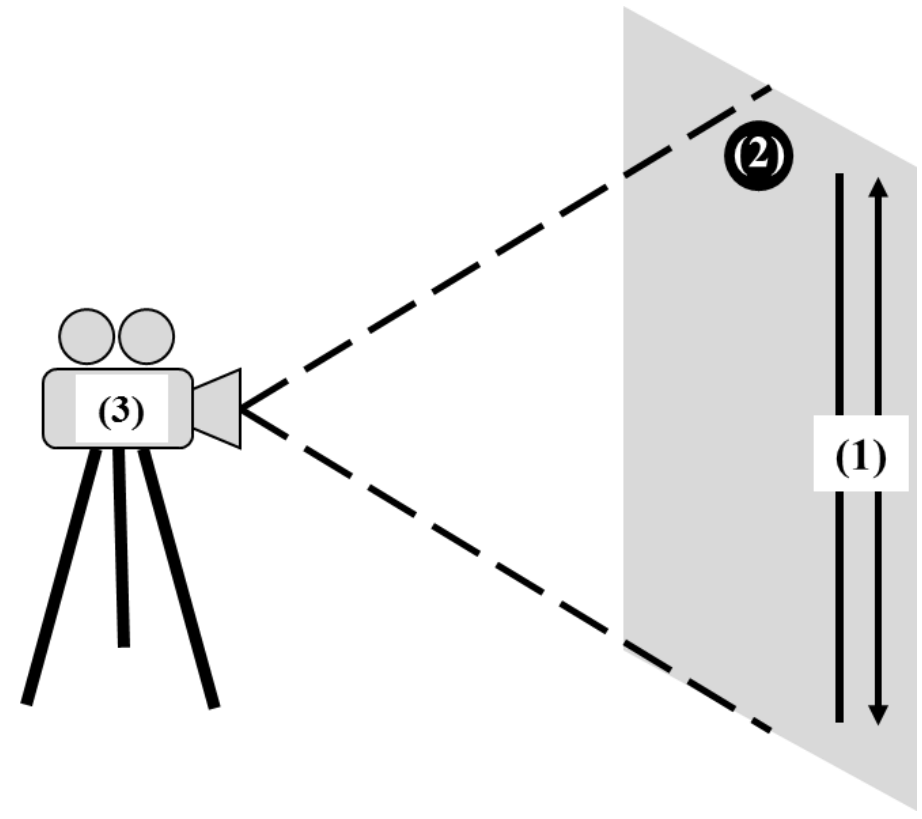

Figure 1. Experimental Setting (1) reference size $(A)$; (2) object; (3) camera.

Measurement of ball position was done by capturing video of ball movement using smartphone camera. In this experiment was used two capturing modes, normal mode 


\section{International Journal of Applied Sciences and Smart Technologies}

Volume 2, Issue 2, pages 157-168

p-ISSN 2655-8564, e-ISSN 2685-9432

and slow-motion mode. The demonstration was conducted by placing the ball at certain height $\left(h_{0}\right)$ facing a camera placed on a tripod. The camera has to be placed so that the whole object motion can be recorded. To measure the height of the ball precisely, a reference size $(A)$ needs to be drawn and shown to camera alongside the ball movement as shown in Figure 1. After being recorded, the video was then analyzed using PowerPoint-based video.
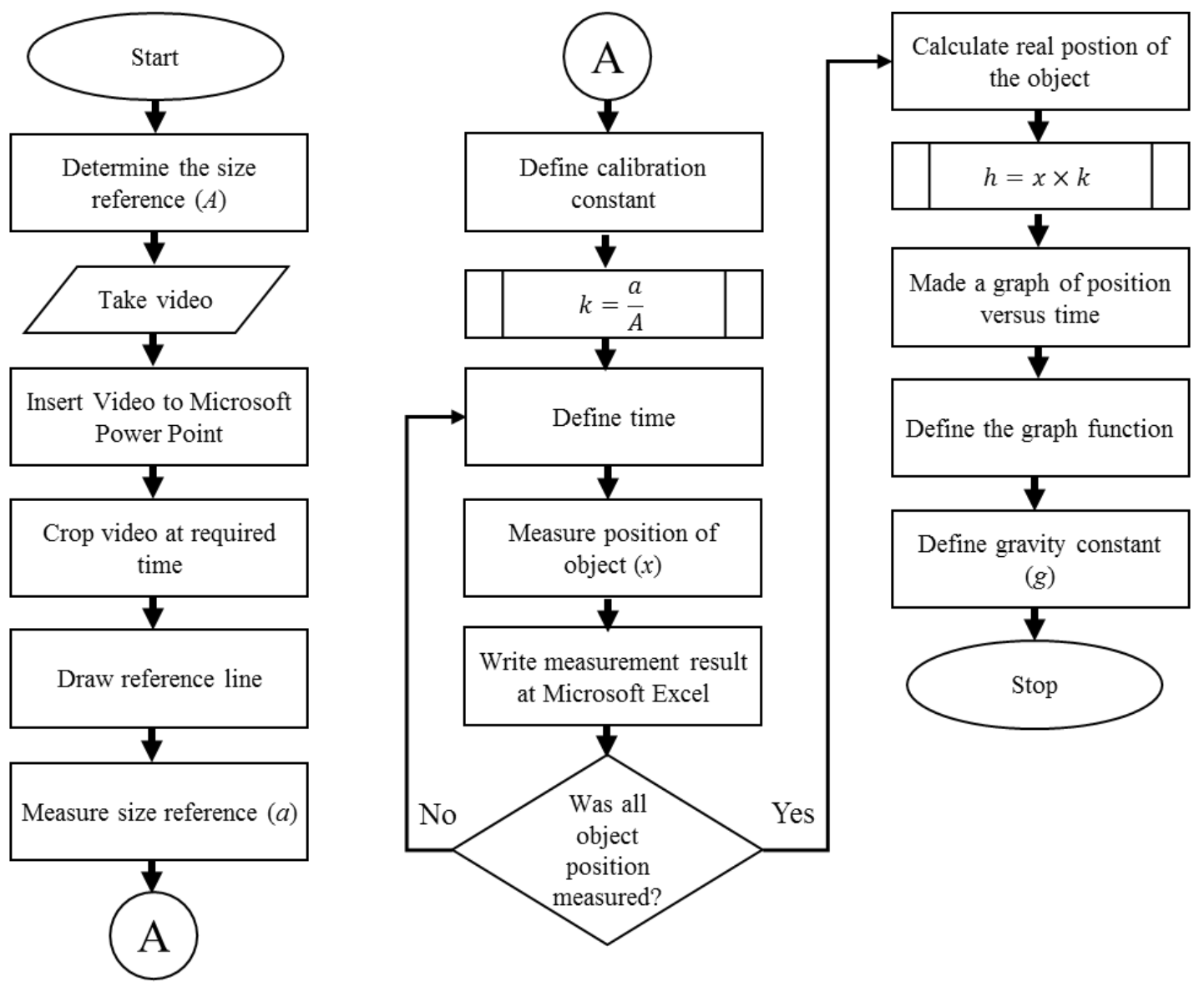

Figure 2. Flowchart of PowerPoint-based Video Analyzer process

The analysis of ball position was done by following the flowchart presented by Figure 2. Firstly, video is inserted to Microsoft PowerPoint and then adjusts the video duration to only show the initial to final object which is required using "trim" feature. Afterward, the length of reference size which was determined is then measured in the captured video by drawing a reference line $(a)$ as shown in Figure 3. By comparing the 


\section{International Journal of Applied Sciences and Smart Technologies}

Volume 2, Issue 2, pages 157-168

p-ISSN 2655-8564, e-ISSN 2685-9432

line length with the actual reference size, the calibration constant is then obtained using equation (1).

$$
k=\frac{a}{A}
$$

This constant will be used to collect the actual ball position $(h)$ from the measured position at video $(x)$ as calculated using equation (2).

$$
h=k x
$$

Repeat the measurement steps for all captured object motion. By plotting the ball position as time function, the relation between ball position and time could be achieved.

In this study, falling motion was demonstrated by dropping the tennis ball from certain height, while the projectile motion was exhibited by throwing a ball inclined at random angle. The initial velocity and angle on projectile motion were not discussed in detail. The tennis ball is chosen because its size and color are easily captured by the camera. In performing the experiment, the measurement of tennis ball was carried out by capturing the bottom edge of the ball.

\section{Results and Discussion}

The measurement results of ball position on falling motion are presented in Figure 4. Based on the results, the ball positions detached from the video are close to the theoretical line. The camera captures objects in the same period for each frame. However, instead of moving in a constant distance, the ball moves with a distance that increases periodically. This shows that the ball's movement is getting faster. By fitting the graph to the quadratic function, the acceleration of the ball is obtained $9.86 \mathrm{~m} / \mathrm{s}^{2}$, which is close to the gravitational acceleration which is $9.82 \mathrm{~m} / \mathrm{s}^{2}$ at the research location [18]. However, according to the theory, the ball acceleration has to be gravitational acceleration which means that the error obtained from the experiment is $0.40 \%$ which is tolerable. 
International Journal of Applied Sciences and Smart Technologies

Volume 2, Issue 2, pages 157-168

p-ISSN 2655-8564, e-ISSN 2685-9432

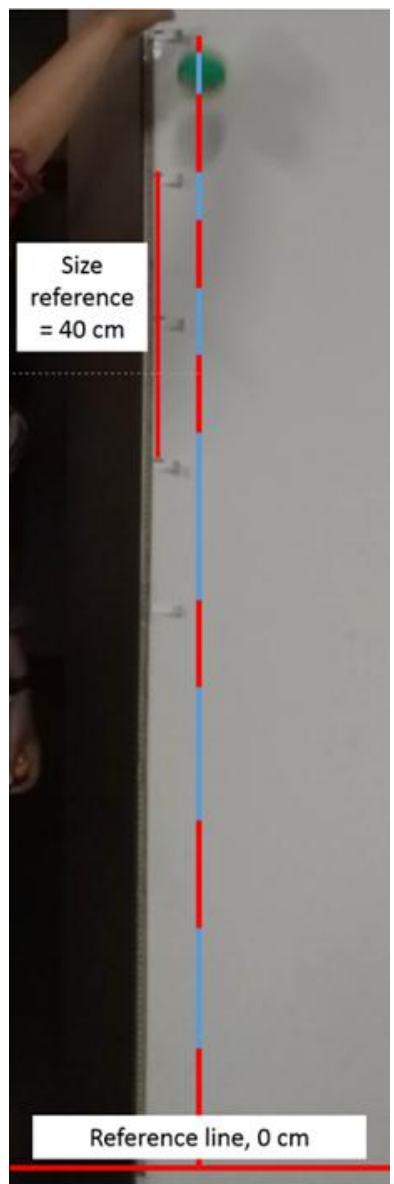

Figure 3. Object position tracking on PowerPoint

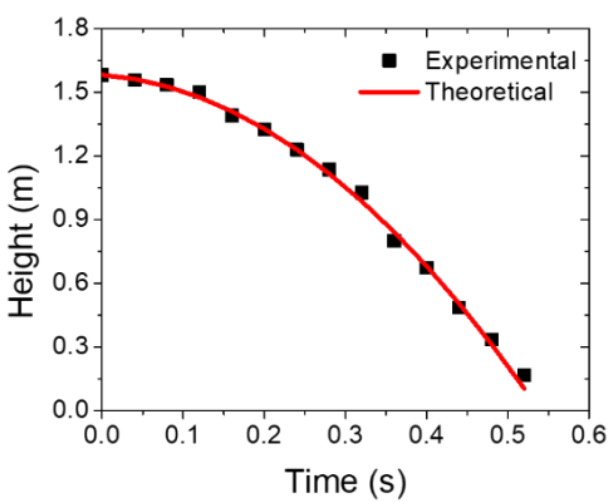

Figure 4. Time-dependent position of ball on falling motion 


\section{International Journal of Applied Sciences and Smart Technologies}

Volume 2, Issue 2, pages 157-168

p-ISSN 2655-8564, e-ISSN 2685-9432

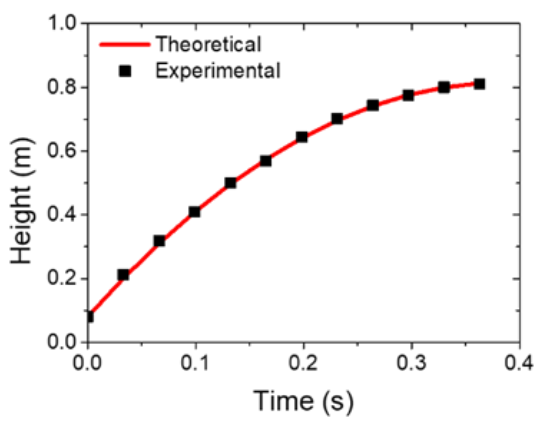

(a)

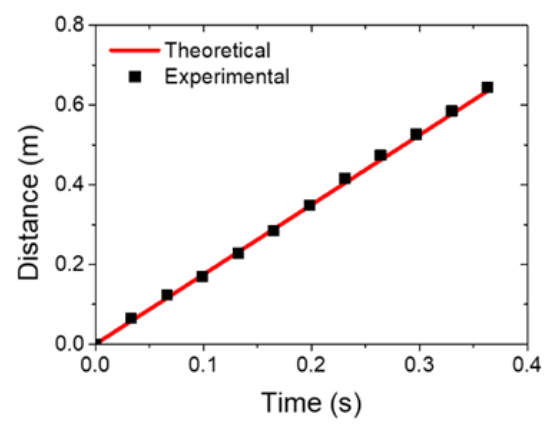

(b)

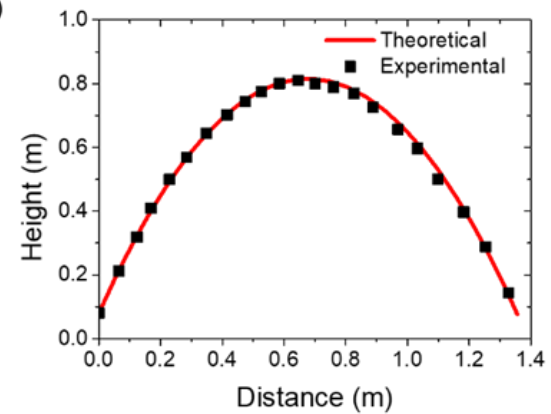

(c)

Figure 5. Time-dependent position of projectile motion (a) vertical motion (upward direction); (b) horizontal motion; (c) ball trajectory on $\mathrm{x}, \mathrm{y}$ axis

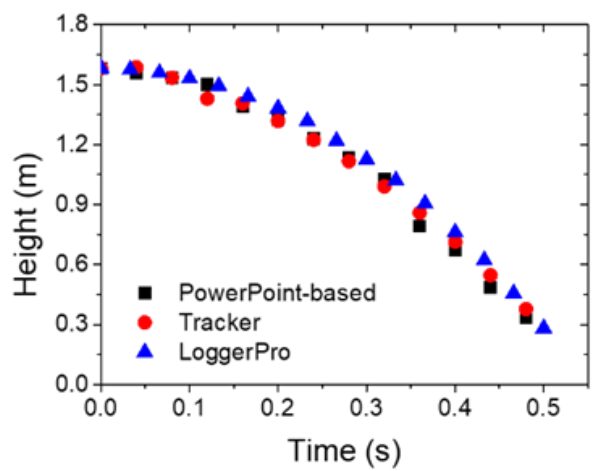

Figure 6. Video Analyzer Comparison on Free-Fall Motion

Figure 5 shows the measurement results of ball position on projectile motion. As aforementioned, the ball movement is demonstrated by throwing the object away at a certain angle without considering the initial velocity and its inclination angle. However, the main focus of this experiment is to enhance the student's concept regarding the projectile motion that is a unification of two independent motions of each axis [18]. Its vertical movement result is shown in Figure 5(a). According to Figure 5(a), the fitting 


\section{International Journal of Applied Sciences and Smart Technologies}

Volume 2, Issue 2, pages 157-168

p-ISSN 2655-8564, e-ISSN 2685-9432

analysis of the experimental data is showing the polynomial trend which is appropriate with the motion with constant acceleration. Further analysis shows that the acceleration is $9.82 \mathrm{~m} / \mathrm{s}^{2}$. This value is close to the gravitational acceleration gained by previous study which achieves a gravitational acceleration of $9.81 \mathrm{~m} / \mathrm{s}^{2}$ [11]. This data is also following the theoretical analysis performed. Meanwhile, the movement at horizontal axis of the experiment is a zero-acceleration motion as shown in Figure 5(b) with the error gained of $3.45 \%$ as depicted on theory [18]. Based on theoretical line in Figure 5 (a) and 5 (b), the initial velocity value is $4.18 \mathrm{~m} / \mathrm{s}$ with a direction of motion of $65.27^{\circ}$ to the horizontal plane. The trajectory pattern of object motion on its horizontal and vertical axes is presented in Figure 5(c). It shows that the ball movement forms a projectile motion as also gained by Klein et.al. [11] with different conditions. This condition depicts that the movements of each axis are independent of each other.

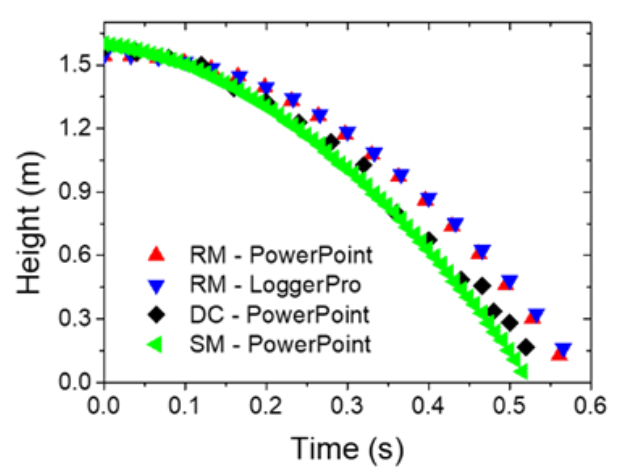

Figure 7. Comparison of Smartphone and Digital Camera

The analyzing method in this study was then compared to the established analyzing methods such as LoggerPro and Tracker to see how the method performed. The result is then presented in Figure 6. As depicted in Figure 6, the PPT-based method is comparable to other methods. It can be seen from the data distribution shown by the PPT-based which close both LoggerPro and Tracker. However, based on the obtained trendlines, the gravitational acceleration gained by those methods is $9.82 \mathrm{~m} / \mathrm{s}^{2}, 8.20$ $\mathrm{m} / \mathrm{s}^{2}$, and $10.76 \mathrm{~m} / \mathrm{s}^{2}$ for PowerPoint-based, Tracker, and LoggerPro, respectively. By 


\section{International Journal of Applied Sciences and Smart Technologies}

Volume 2, Issue 2, pages 157-168

p-ISSN 2655-8564, e-ISSN 2685-9432

this condition, the proposed method can be an alternative solution to perform the analysis of kinematic videos.

As aforementioned, in this study, feasibility of smartphone camera on performing a kinematic motion experiment was also investigated. This smartphone camera was used to record a free-fall motion experiment. The result is shown in Figure 7. According to Figure 7, object position tracked by smartphone camera (RM) is clearly recorded as like a digital camera (DC) due to the same of their frame rate. However, using a higher resolution, the smartphone camera shows a brighter video to be analyzed [19]. Also, from Figure 7, the video analyzation performed by Power-Point (RM - PowerPoint) is close to LoggerPro (RM - LoggerPro) results as like as Figure 6. The PowerPoint result gives a gravitational acceleration are $9.64 \mathrm{~m} / \mathrm{s}^{2}$ and LoggerPro $9.23 \mathrm{~m} / \mathrm{s}^{2}$. By assuming that the gravitational acceleration at research location is $9.82 \mathrm{~m} / \mathrm{s}^{2}$, then the deviation gained by PowerPoint-based video analyzer 4\% lower than LoggerPro result. However, this result is highly dependent on user accuracy in marking the object's position. But Power-Point makes it possible to zoom in on the video so that it helps in increasing accuracy. It shows that PowerPoint-based is reliable to be used in the experiment.

Nowadays, many manufacturers embed their smartphone camera with slow-motion feature. By using this effect, the video frame rate can be adjusted to be higher, in this case, the frame rate is $125 \mathrm{fps}$. As can be seen from Figure 7, slow-motion (SM) effect gives a rapid video tracking than regular mode (RM) due to the higher resolution, so the motion can be tracked flawlessly [20]. At this stage, the resolution of the experiment can be higher. However, to give a better understanding of constant-acceleration motion, the regular mode is more reliable. It is caused by the condition of motion that can be observed clearly. Since the camera resolution on smartphone nowadays is around 16 MP or above, it will give an outstanding object tracking. Then, the use of PowerPointbased video analyzer makes the analysis easy, without being worried by its inaccuracy.

\section{Conclusions}

The use of smartphone camera and PowerPoint-based video analyzer has been successfully used to record and analyze the motion on kinematic experiments. The 


\section{International Journal of Applied Sciences and Smart Technologies}

Volume 2, Issue 2, pages 157-168

p-ISSN 2655-8564, e-ISSN 2685-9432

results show that the object motion can be well tracked, and the ball trajectory can be reconstructed. Gravitational accelerations gained by the method are $9.86 \mathrm{~m} / \mathrm{s}^{2}$ for free fall experiment and $9.82 \mathrm{~m} / \mathrm{s}^{2}$ for projectile experiments which are comparable to theory value with error gained below $1 \%$. The results also present that PowerPoint-based method is comparable to the established one such as Tracker and LoggerPro. Moreover, the use of smartphone camera and this PowerPoint method can perfectly track the object movement, even better than the use of established one. By using this combination method, the physics learning on kinematic motion can be well delivered to students and hopefully can decrease student misconceptions of the subject.

\section{References}

[1] P. Wattanayotin, C. Puttharugsa, and S. Khemmani, "Investigation of the rolling motion of a hollow cylinder using a smartphone's digital compass." Phys. Educ. 52, 045009, 2017.

[2] C. Puttharugsa, S. Khemmani, P. Utayarat, and W. Luangtip, "Investigation of the rolling motion of a hollow cylinder using a smartphone.” Eur. J. Phys. 37, 055004, 2016.

[3] A. Hamidah, E. N. Sari, and R. S. Budianingsih, "Persepesi Siswa tentang Kegiatan Praktikum Biologi di Laboratorium SMA Negeri Se-kota Jambi.” J. Sainmatika. 8, 49-59, 2014.

[4] L. K. Wee, C. Chew, G. H. Goh, S. Tan, and T. L. Lee, "Using Tracker as a pedagogical tool for understanding projectile motion." Phys. Educ. 47, 448-455, 2012.

[5] M. Basta, M. D. Gennaro, and V. Picciarelli, "A desktop apparatus for studying rolling motion." Phys. Educ. 34, 371-375, 1999.

[6] S. Phommarach, P. Wattanakasiwich, and I. Johnston, "Video analysis of rolling cylinders." Phys. Educ. 47, 189-196, 2012.

[7] F. Vera, and C. Romanque, "Another Way of Tracking Moving Objects Using Short Video Clips.” Phys. Teach. 47, 370-373, 2009.

[8] E. L. Medeiros, O. A. P. Tavares, and S. B. Duarte, "Inexpensive Strobe-like Photographs." Phys. Teach. 47, 536-541, 2009. 


\section{International Journal of Applied Sciences and Smart Technologies}

Volume 2, Issue 2, pages 157-168

p-ISSN 2655-8564, e-ISSN 2685-9432

[9] T. Terzella, J. Sundermier, J. Sinacore, C. Owen, and H. Takai, "Measurement of g Using a Flashing LED.” Phys. Teach. 46, 395-397, 2008.

[10] J. Bonato, L. M. Gratton, P. Onorato, and S. Oss, "Using high speed smartphone cameras and video analysis techniques to teach mechanical wave physics." Phys. Educ. 52, 045017, 2017.

[11] P. Klein, S. Gröber, J. Kuhn, and A. Müller, "Video analysis of projectile motion using tablet computers as experimental tools." Phys. Educ. 49, 37-40, 2014.

[12] A. Mazzella, and I. Testa, "An investigation into the effectiveness of smartphone experiments on students' conceptual knowledge about acceleration." Phys. Educ. 51, 055010, 2016.

[13] L. A. Testoni, and G. Brockington, "The use of smartphones to teach kinematics: an inexpensive activity." Phys. Educ. 51, 063008, 2016.

[14] R. D. Septianto, D. Suhendra, and F. Iskandar, "Utilisation of the magnetic sensor in a smartphone for facile magnetostatics experiment: magnetic field due to electrical current in straight and loop wires.” Phys. Educ. 52, 015015, 2017.

[15] J. A. Bryan, "Investigating the conservation of mechanical energy using video analysis: four cases.” Phys. Educ. 45, 50-57, 2009.

[16] J. K. Jones, A. Krow, S. Hariharan, and L. Weekes, "Measuring angles on digitalized radiographic images using Microsoft PowerPoint." West Indian Med. J. 57, 14-19, 2008.

[17] R. S. Meza, Sagittal cephalometric diagnosis using Power Point (Microsoft ${ }^{\circledR}$ Office) Rev. Mex. Ortod. 4. e8-16, 2016.

[18] D. Halliday, R. Resnick, and J. Walker, Fundamentals of Physics (John Wiley \& Sons), 2010.

[19] M. Cruz, R. F. Cruz, E. A. Krupinski, A. M. Lopez, R. M. McNeeley, and R. S. Weinstein, "Research Note: Effect of Camera Resolution and Bandwidth on Facial Affect Recognition Telemed.” J. e-Health. 10, 392-402, 2004.

[20] E. B. Blackford, and J. R. Estepp, "Effects of frame rate and image resolution on pulse rate measured using multiple camera imaging photoplethys mography." Proc. SPIE. 9417, 2015. 
International Journal of Applied Sciences and Smart Technologies

Volume 2, Issue 2, pages 157-168

p-ISSN 2655-8564, e-ISSN 2685-9432

This page intentionally left blank 